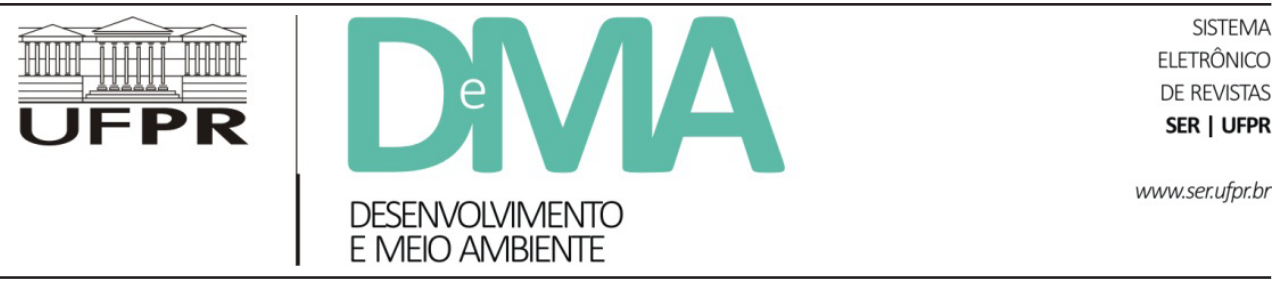

\title{
Conflitos espaciais entre instrumentos legais de planejamento territorial: caso de estudo na região do Balneário Cassino (Rio Grande, RS)
}

\section{Spatial Conflicts Among Legal Instruments of Territorial Planning: Case Study in the Casino Beach Region (Rio Grande, RS)}

\author{
Marcela de Avellar MASCARELLO ${ }^{1 *}$, Tiago Borges Ribeiro GANDRA ${ }^{1}$, Jean Marcel de Almeida ESPINOZA ${ }^{1}$, \\ Milton Lafourcade ASMUS ${ }^{2}$ \\ ${ }^{1}$ Instituto Federal de Educação Ciência e Tecnologia do Rio Grande do Sul (IFRS), Rio Grande, RS, Brasil. \\ ${ }^{2}$ Universidade Federal do Rio Grande (FURG), Rio Grande, RS, Brasil. \\ *E-mail de contato: mascarellomarcela@gmail.com
}

Artigo recebido em 2 de junho de 2016, versão final aceita em 11 de agosto de 2016.

RESUMO: O presente artigo apresenta a aplicação de uma metodologia com ferramentas de geoprocessamento a fim de verificar a existência (ou não) de conflitos espaciais entre instrumentos de ordenamento territorial na região do Balneário Cassino e adjacências, no município de Rio Grande-RS. Para tanto, foram analisados os instrumentos legais: Unidades de Planejamento, componente do Plano Diretor Municipal; Zoneamento Ecológico Econômico Municipal -ZEEM, componente do Plano Ambiental Municipal; e Mapa da Base Legal Ambiental, gerado pelos autores baseado nas Áreas de Preservação Permanente - APPs, Unidades de Conservação e demais áreas com restrição de uso legalmente definidas. Utilizou-se o software de Sistemas de Informações Geográficas QGIS, uma imagem do satélite RapidEye ${ }^{\circledR}$ e dados vetoriais para o processamento. Foram gerados como produtos: mapa de cobertura do solo, mapa da base legal ambiental e mapas de conflitos a partir do cruzamento dos dados. Verificou-se que a classe com maiores áreas de cobertura do solo foram os campos $(50,5 \%)$, seguidos por banhados e marismas (25,2\%). E que 34,55\% da área mapeada corresponde a áreas legalmente protegidas. Quanto aos dados de conflitos, foi possível verificar problemas de escala, sobretudo nas bordas, pois as Unidades de Planejamento estão em escala de 1:10.000, enquanto que o ZEEM está em escala 1:100.000 e o Mapa de Base Legal Ambiental está em escala 1:25.000. Outro problema encontrado foi a omissão das Unidades de Planejamento para grande parte da área de estudo. Verificou-se também a importância da delimitação das APPs e que a sobreposição destes ambientes com as outras duas políticas públicas resolveria boa parte dos conflitos espaciais encontrados. $\mathrm{O}$ fato é que existem dois instrumentos de políticas públicas para um mesmo território que se conflitam, o que evidencia a importância da integração das instituições públicas e dos dados geoespaciais na regulação e gestão do território.

Palavras-chave: geoprocessamento; área de preservação permanente; instrumentos legais de planejamento territorial; conflitos; zoneamento. 
ABSTRACT: This article presents the application of a methodology with geoprocessing tools to verify the existence (or not) of spatial conflicts between land use organizing instruments in the Casino Beach region and surrounding areas in the municipality of Rio Grande-RS. Therefore, the following legal instruments were analyzed: Planning Units, the Master Plan component, Ecological Economic Zoning Municipal- ZEEM, the Municipal Environmental Plan component and Map of Environmental Legal Basis generated by the authors based on Permanent-APPs Preservation Areas, Units Conservation and other areas with legally defined usage restrictions. We used the software Geographic Information Systems QGIS; one satellite image RapidEye ${ }^{\circledR}$ and vector data for processing. They resulting products were: land cover map, the environmental legal basis map and maps of conflicts based on crossing data. It was found that the class with largest soil coverage areas are fields $(50.5 \%)$, followed by swamps and marshland (25.2\%). And that $34.55 \%$ of the mapped area correspond to legally protected areas. As for the data conflicts, we found scale problems especially at the edges because the Planning Units are in scale of 1: 10,000; while ZEEM is 1: 100,000 and the Environmental Legal Basis is in scale 1:25.000. Another problem encountered was the failure of the Planning Units for most of the study area. It was also found the importance of delimiting the PPAs and that the overlap of these environments with the other two policies would solve much of the spatial conflicts found. The fact is that there are two instruments of public policy for the same territory that are in conflict, which highlights the importance of integrating public institutions and geospatial data in the regulation and management of the territory.

Keywords: GIS; permanent preservation area; legal instruments of territorial planning; conflicts; zoning.

\section{Introdução}

As zonas costeiras são ambientes de muitos conflitos de interesses com relação ao uso e à ocupação dos ecossistemas que as compõem. Possuem ecossistemas imprescindíveis para a manutenção da vida, geram alta produtividade biológica (o que potencializa práticas de extração tradicionais e industriais, como a pesca) e valor cênico e recreacional (que faz com que sejam alvo do turismo e atraiam, cada vez mais, moradores em busca de "qualidade de vida"). Ao mesmo tempo, tais ecossistemas ocorrem em localizações estratégicas para a economia, abrigando portos, indústrias, geração de energia e mineração (Cicin-Sain \& Knecht, 1998). Estas atividades econômicas nem sempre ocorrem de forma ajustada ao seu contexto ecossistêmico, gerando efeitos socioambientais indesejados e conflitos de uso (Polette \& Asmus, 2015).

Tais situações requerem a elaboração e a implementação de políticas públicas e instrumentos de gestão e ordenamento territorial que compatibilizem a ocorrência das várias atividades, buscando minimizar seus impactos negativos e distribuí-las de forma adequada no espaço.

No Brasil, o surgimento dos instrumentos de ordenamento territorial ocorreu, predominantemente, a partir da pressão internacional gerada pela Primeira Conferência Mundial sobre o Homem e o Meio Ambiente - Conferência de Estocolmo, em 1972. Houve a institucionalização do planejamento urbano nas administrações municipais, a partir da década de 70, bem como a adoção da Política Nacional do Meio Ambiente (PNMA) em 1981, que introduziu os Zoneamentos Ambientais como instrumentos de políticas públicas no Brasil (Santos \& Mascarello, 2012).

No entanto, apesar desse arcabouço político e legal, vários municípios costeiros brasileiros apresentam, por várias razões, efeitos negativos como resultado do uso econômico e da ocupação de seus territórios e dos ecossistemas que os caracterizam.

Rio Grande está localizado no extremo sul do Brasil. O município possui elevada relevância ambiental pela diversidade de ecossistemas, como dunas, banhados, marismas, estuário, praia, 
campos, entre outros. Por outro lado, possui alta relevância econômica, caracterizada: (1) por sua posição estratégica em relação ao Mercosul, (2) pela integração de diversos meios viários, como as rodovias, ferrovias, hidrovias e via marítima, (3) pela presença de um significativo distrito industrial junto ao Porto Organizado, (4) pela recorrente isenção fiscal e grandes investimentos estatais em obras de infraestrutura (Mascarello \& Santos, 2015). Estes atrativos geográficos, estruturais, políticos e econômicos estimulam atividades econômicas de alto impacto ambiental, como a portuária, de construção naval, refinaria de petróleo, armazenagem de produtos químicos, monocultivos, bovinocultura, entre outras. Desta forma, torna-se imprescindível um ordenamento territorial que possa minimizar os conflitos entre as diversas atividades presentes na região e a saúde de seu ambiente e o bem-estar social de sua comunidade.

No município, os dois principais instrumentos que regulam os usos do território são o Plano Diretor (no planejamento urbano) e o Plano Ambiental Municipal (no contexto ambiental). O Plano Diretor foi instituído por lei em 2008 e o Plano Ambiental Municipal, elaborado em 2005, não foi instituído na forma de lei, apesar de ser frequentemente consultado em tomadas de decisões. O Plano Diretor possui, como anexo, o Mapa de Unidades de Planejamento (UPs), que determina os limites das UPs e quais são os usos permitidos para cada unidade. O Plano Ambiental Municipal estabelece o Zoneamento Ecológico-Econômico Municipal (ZEEM), que determina as áreas de preservação, conservação, desenvolvimento e recuperação ambiental, bem como um mapa da base legal, que permite verificar a localização geográfica das áreas de restrição de uso, como as Áreas de Preservação Permanente (APP) e as Unidades de Conservação (UC).

Entretanto, estes instrumentos foram elaborados em tempos, escalas e bases cartográficas diferentes e podem ser, em muitos casos, contraditórios. As escalas do ZEEM e do mapa da base legal ambiental não são adequadas para o perímetro urbano e consideram como base o antigo Código Florestal (1965), regulamentado pela resolução CONAMA 303/2002, que foi substituído pelo novo Código Florestal Brasileiro (Lei no 12.651) (Brasil, 2012). Portanto, é necessário elaborar um novo mapa legal em escala adequada ao perímetro urbano e que leve em consideração a legislação atual. Neste contexto, o objetivo desse artigo é verificar a consistência espacial entre os instrumentos legais de ordenamento territorial (UPs e ZEEM) e o mapa da base legal ambiental gerado em escala compatível à gestão urbana em Rio Grande.

\section{2. Área de estudo}

Este trabalho consiste em uma primeira aproximação metodológica, portanto, se optou em fazer um recorte espacial enfocado em uma cena da imagem do satélite RapidEye ${ }^{\circledR}$. A análise foi realizada para a região do Balneário Cassino e áreas adjacentes por tratar-se de uma área complexa, abrangendo todos os tipos de uso e de cobertura do solo existentes no município. Por outro lado, é uma área que vem sofrendo uma expansão urbana intensa nos últimos anos, o que ressalta a importância de se definir os ambientes sensíveis e os espaços protegidos por lei. A área delimitada para este estudo é de $236 \mathrm{~km}^{2}$, o que corresponde a $8,4 \%$ da área total do município (Figura 1). 


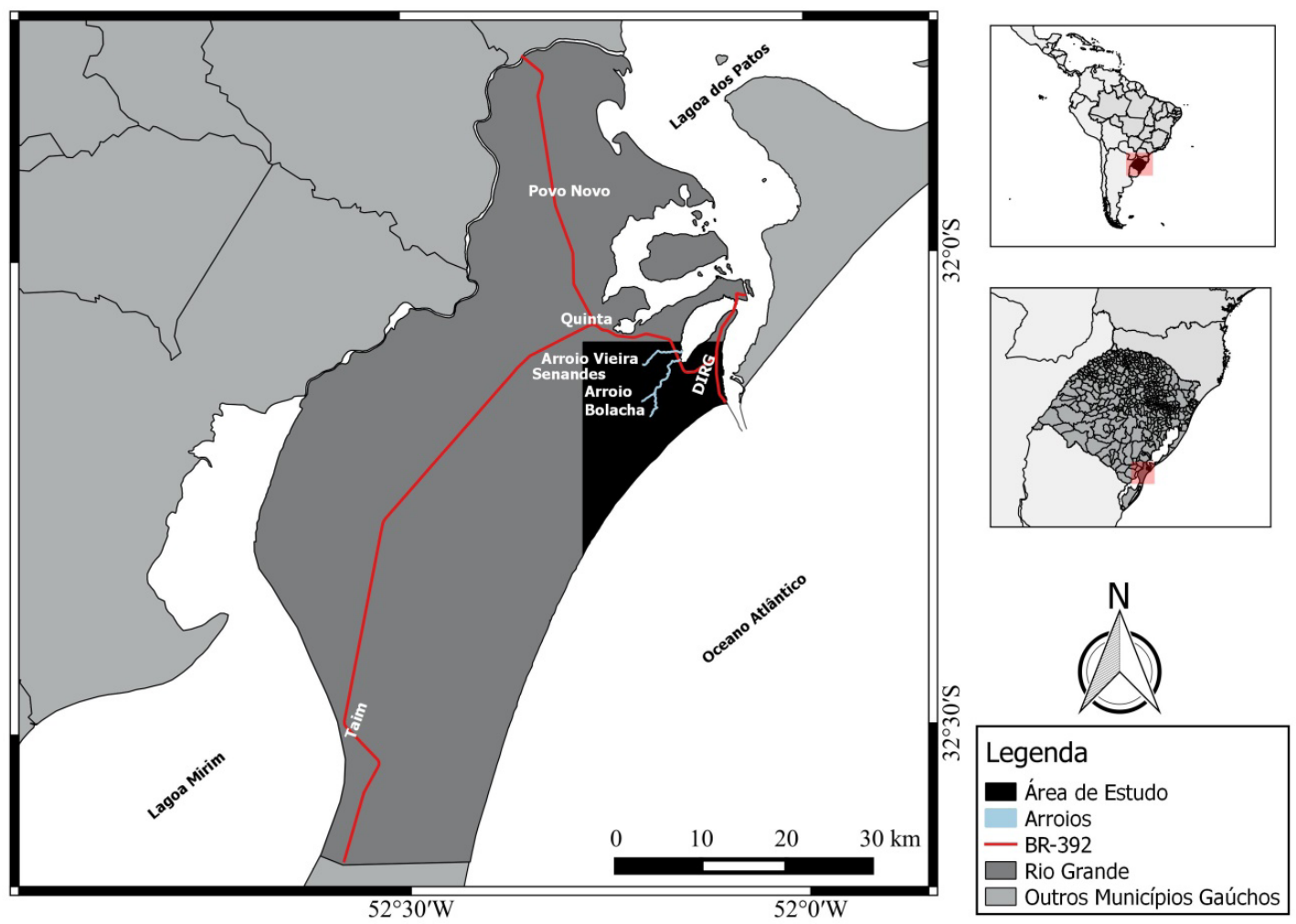

FIGURA 1 - Localização da área de estudo.

\section{Conceitos e definições}

\subsection{Ordenamento territorial em Rio Grande}

A ideia de que compete ao governo federal assumir de forma coordenada as questões do ordenamento territorial remonta aos anos 80 , se institucionalizando por meio da Constituição Federal de 1988 (art. 21, Parágrafo IX) que diz: "Compete à União elaborar e executar planos nacionais e regionais de ordenação do território e de desenvolvimento econômico e social" (Brasil, 1988).

O Plano Nacional de Ordenamento do Território (Ministério da Integração Nacional, 2006) define:
Ordenamento territorial é a regulação das ações que têm impacto na distribuição da população, das atividades produtivas, dos equipamentos e de suas tendências, assim como a delimitação de territórios de populações indígenas e populações tradicionais, e áreas de conservação no território nacional ou supranacional, segundo uma visão estratégica e mediante articulação institucional e negociação de múltiplos atores.

Neste trabalho, se optou por utilizar este conceito, pois se entende que tanto as políticas de planejamento urbano como as políticas ambientais, ao tratarem de questões relacionadas ao território e das relações sociais, são políticas de ordenamento territorial. Desta forma, os instrumentos de políticas públicas de instância municipal aqui analisados são 
de uma política urbana (Plano Diretor) e de uma política ambiental (Plano Ambiental Municipal; ZEEM). Portanto, faz-se necessário defini-los.

O plano diretor aparece na Constituição (Brasil, 1988) em seu artigo 182, parágrafo primeiro, como instrumento básico da política de desenvolvimento e de expansão urbana. Mas é no ano de 2001 que é instituída a lei conhecida como Estatuto das Cidades, que estabelece diretrizes da política urbana, determinando a necessidade de planos diretores para cidades com mais de 20.000 habitantes. Indica importantes diretrizes, como a necessidade de participação cidadã, bem como aspectos técnicos, como a elaboração de mapas temáticos sobre o território, de caracterização e distribuição da população e seus movimentos, de uso do solo, de infraestrutura urbana e de atividade econômica do município (Brasil, 2001).

O plano diretor é, portanto, um instrumento de política urbana instituído pelo Ministério das Cidades a fim de planejar o futuro da cidade, com participação e incorporação de todos os setores sociais, e constitui-se como instrumento básico para orientar a política de desenvolvimento e de ordenamento da expansão urbana do município (Ministério das Cidades, 2005).

Quanto à política ambiental, cabe ressaltar a instituição da Política Nacional do Meio Ambiente, onde, pela primeira vez, se fala na legislação brasileira sobre planos ambientais. Dispõe no seu artigo $5^{\circ}$ :

As diretrizes da Política Nacional do Meio Ambiente serão formuladas em normas e planos, destinados a orientar a ação dos Governos da União, dos Estados, do Distrito Federal, dos Territórios e dos Municípios no que se relaciona com a preservação da qualidade ambiental e manutenção do equilíbrio ecológico, observados os princípios estabelecidos no art. $2^{\circ}$ desta Lei. (Brasil, 1981).
O Zoneamento Ecológico Econômico - ZEE, por sua vez, somente foi regulamentado pelo decreto n. 4.297, de 10 de julho de 2002, e o artigo 2 o define como:

\begin{abstract}
Instrumento de organização do território a ser obrigatoriamente seguido na implantação de planos, obras e atividades públicas e privadas, estabelece medidas e padrões de proteção ambiental destinados a assegurar a qualidade ambiental, dos recursos hídricos e do solo e a conservação da biodiversidade, garantindo o desenvolvimento sustentável e a melhoria das condições de vida da população (Brasil, 2002).
\end{abstract}

Em 2000, no Estado do Rio Grande do Sul, foi instituído o Código Estadual do Meio Ambiente, por meio da Lei estadual n. 11.520, de 03 de agosto de 2000 (Rio Grande do Sul, 2000). Esta lei delega aos municípios o licenciamento ambiental dos empreendimentos e atividades consideradas como de impacto local, levando em conta a resolução CONAMA 237 (CONAMA, 1997). No mesmo ano, a resolução CONSEMA 004 dispõe sobre os critérios para o exercício da competência municipal do licenciamento ambiental e estabelece, entre outros requisitos, que o município possua um plano ambiental municipal e um Zoneamento Ecológico-Econômico (ZEEM) aprovados pelo Conselho Municipal de Defesa do Meio Ambiente - COMDEMA.

O Plano Diretor do Rio Grande, de 2008, estabelece no seu capítulo III referente à Política Ambiental Municipal, no parágrafo II do artigo 40, a elaboração do Plano Ambiental Municipal. O Plano Municipal, por sua vez, estabelece em seu segundo princípio orientador que "o Município, em pleno acordo com o Conselho Gestor do Rio Grande, estabelecerá um zoneamento que defina os limites ecológicos para o uso do solo, tendo em vista as necessidades de conservação da biodiversi- 
dade." E o Plano Ambiental Municipal dispõe que o ZEEM deve estar em consonância com o Plano Diretor Municipal.

\subsection{Areas de Preservação Permanente (APP)}

O Código Florestal de 1965, substituído pela Lei $n^{\circ} 12.651$, de 25 de maio de 2012, contempla a criação de áreas de preservação permanente - APP, as quais são fundamentadas por diversas outras normativas e tratados internacionais. O novo Código Florestal (Brasil, 2012), em seu artigo $3^{\circ}$, segundo parágrafo, define APP como:

Área protegida, coberta ou não por vegetação nativa, com a função ambiental de preservar os recursos hídricos, a paisagem, a estabilidade geológica e a biodiversidade, facilitar o fluxo gênico de fauna e flora, proteger o solo e assegurar o bem-estar das populações humanas.

A referida lei ainda estabelece critérios e substitui diversas definições instituídas anteriormente pela resolução CONAMA 303, de 2002.

A gestão destas áreas é um desafio, a fim de garantir sua proteção integral. Mas para proteger é necessário saber o que existe, onde existe, quanto existe e seu estado de conservação. Nesse sentido, as metodologias possíveis de serem implementadas por meio do geoprocessamento tornam-se alternativas viáveis para reduzir de maneira significativa as deficiências relativas ao cumprimento das leis pertinentes (Nascimento et al., 2005), o que é reafirmado por Ribeiro et al. (2005), quando dizem que a delimitação automática das APPs elimina a subjetividade do processo, viabilizando o fiel cumprimento da lei, favorecendo a fiscalização ambiental, e com isto impossibilitando que continue a se propagar o discurso de dificuldades conjunturais e deficiências estruturais para continuar promovendo impunemente a degradação ambiental.

\section{Materiais e métodos}

A metodologia foi desenvolvida nos softwares livres QGIS 2.12 e GRASS 6.4. Os dados secundários utilizados foram obtidos de forma gratuita a partir da cessão por parceiros, arquivos disponibilizados na internet e imagem orbital disponibilizada pelo Ministério do Meio Ambiente para instituições públicas. O detalhamento da metodologia pode ser verificado na Figura 2.

\subsection{Elaboração do mapa de cobertura do solo}

O mapa de cobertura do solo foi produzido a partir de dados obtidos por meio de sensor remoto (imagem orbital) utilizando a classificação multiespectral, que consiste no

processo de associar os pixels da imagem a um nú-
mero finito de classes individuais que representam
os objetos do mundo real, com base nos seus valores
digitais. Se um pixel satisfaz um determinado conjunto
de critérios, normalmente avaliados por medidas esta-
tísticas, o pixel é atribuído à classe que melhor satisfaz
os critérios estabelecidos. (Meneses \& Sano, 2012).

Ela pode ser feita utilizando uma diversidade de métodos como: algoritmos paramétricos ou não paramétricos; classificação supervisionada ou não supervisionada; e por pixel ou por regiões (Jensen, 2005; Meneses \& Sano, 2012).

Neste trabalho, optou-se por utilizar: algoritmos paramétricos, uma vez que utilizam parâmetros estatísticos, como média e matriz de covariância para definir os limiares de cada classe, apresentando 


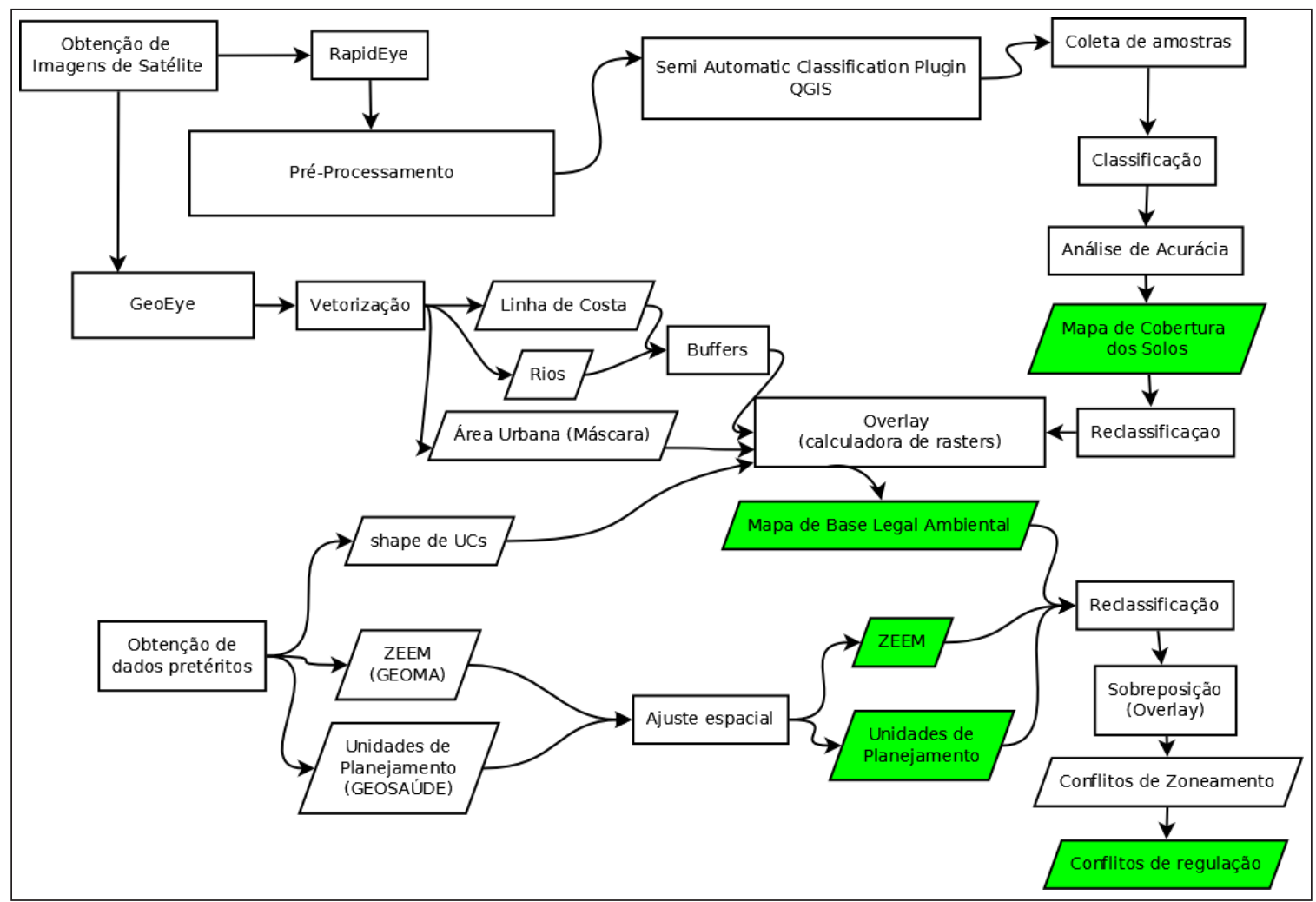

FIGURA 2 - Fluxograma da metodologia utilizada no desenvolvimento da pesquisa.

problema para imagens mais heterogêneas, como as urbanas, mas sendo o método mais adequado para cenas naturais (Andrade et al., 2014); classificação supervisionada, em que o operador define o número de classes e o espectro (da amostra) que corresponde a cada uma delas, sendo o mais adequado quando se conhece bem a área de estudo; e método pixel-a-pixel, que classifica pixel por pixel de acordo com sua proximidade com o valor espectral da amostra ou se está dentro do limiar de uma dada classe (Jensen, 2005; Meneses \& Sano, 2012).

Para a elaboração do Mapa de Cobertura do Solo, foi utilizada uma imagem proveniente da Constelação de Satélites alemã RapidEye ${ }^{\circledR}$, que opera com o Sensor REIS (RapidEye Earth Imaging System), com resolução espectral de 5 bandas espectrais (Tabela 1) e resolução espacial de 5 metros, coletando informações de grandes áreas e com alta capacidade de revisita (24h).

TABELA 1 - Bandas espectrais e respectivos comprimentos de onda nas imagens RapidEye ${ }^{\circledR}$

\begin{tabular}{cc}
\hline Banda & Faixa espectral \\
\hline Azul & $440-510$ \\
Verde & $520-590$ \\
Vermelho & $630-685$ \\
Red Edge & $690-730$ \\
Infravermelho & $760-850$ \\
\hline
\end{tabular}

FONTE: Adaptado de: <http://blackbridge.com/rapideye/>. 
Estas imagens ganharam importância no cenário nacional com a assinatura de convênios com o governo federal, que passou a fornecer as mesmas gratuitamente para os órgãos públicos, tendo como principal objetivo a realização do cadastro ambiental rural (Mengatto Júnior \& Silva, 2014).

A escolha da imagem de satélite para o desenvolvimento desta pesquisa deu-se por ser facilmente replicável pelo baixo custo de operacionalização. A resolução de 5 metros é adequada para a escala de decisão, produzindo uma informação com escala de 1:25.000. Para aplicações ambientais, a resolução dos dados RapidEye ${ }^{\circledR}$ responde adequadamente à caracterização das classes de interesse, enquanto imagens de altíssima resolução poderiam acarretar classificações espúrias. Em imagens de altíssima resolução (pixel menor do que $1 \mathrm{~m}$ ), é comum haver confusão na classificação devido aos pequenos objetos que podem ser irrelevantes para o objetivo proposto, além do alto custo de obtenção e da necessidade de maior capacidade computacional para o processamento (Gonzales \& Woods, 2009).

Foi escolhida a imagem mais recente e com menor cobertura de nuvens disponível no Geocatálogo do Ministério do Meio Ambiente ${ }^{1}$, que corresponde ao dia 05 de janeiro de 2014. A imagem disponibilizada é georreferenciada e com as bandas fusionadas. Portanto, na fase de pré-processamento, só foi necessário realizar a calibração radiométrica, que foi feita com o plugin GEOSUD TOA Reflectance ${ }^{2}$.

A classificação das imagens foi realizada com o Semi-Automatic Classification Plugin. Para isto, foram coletadas as imagens áreas de amostra de 7 classes: (1) oceano e lagoas; (2) dunas; (3) solo exposto; (4) campos; (5) matas exóticas; (6) matas nativas; e (7) banhados e marismas. A escolha por juntar os ecossistemas banhados e marismas se deu devido à semelhança espectral entre os dois, o que dificultaria a classificação. Além disso, estes dois ecossistemas são considerados APPs, o que não afetaria resultados de mapeamento de áreas protegidas.

Parte das áreas de amostra não foi utilizada na fase de classificação e foi guardada para a posterior análise de acurácia dos mapas de usos dos solos. A análise de acurácia foi realizada por meio do indíce Kappa. Foram testados três métodos de classificação: mínima distância (MinDist), máxima verossimilhança (MaxLike) e menor ângulo espectral (SAM).

No mapa com melhor acurácia, foi aplicado um filtro espacial de passa-baixa, que diminui a quantidade de pixels isolados dentro de uma determinada classe. Isto foi realizado por meio de convolução em janela de $5 \times 5$ pixels, utilizando a moda entre os vizinhos.

\subsection{Aquisição e processamento de dados vetoriais}

Nesta etapa, foram utilizados dados vetoriais primários e secundários, sendo dentre estes últimos alguns adaptados de fontes oficiais (IBGE) e outros cedidos por grupos de pesquisa do Instituto Federal de Educação, Ciência e Tecnologia do Rio Grande do Sul, Campus Rio Grande, e Universidade Federal do Rio Grande - FURG.

As áreas urbanas consolidadas, Rios, Linha de Costa da Lagoa e Adutora foram vetorizados em

\footnotetext{
http://geocatalogo.mma.gov.br/

2 Este plugin faz a calibração das imagens produzindo a reflectância dos alvos no topo da atmosfera e, portanto, não minimiza as interferências da atmosfera terrestre na resposta espectral dos alvos. Disponível em: $<$ https://plugins.qgis.org/plugins/geosudRefToa/> .
} 
tela em escala de 1:5.000. Os arquivos shapefile ${ }^{3}$ da APA da Lagoa Verde e Linha de Costa Marinha foram disponibilizados pelo Grupo de Pesquisa Geotecnologias e Meio Ambiente (GEOMA), do Instituto Federal de Educação, Ciência e Tecnologia do Rio Grande do Sul (IFRS). As Áreas de Preservação (APs) do Distrito Industrial do Rio Grande (DIRG) foram produzidas no contexto do Plano Diretor do Distrito Industrial (Silva \& Asmus, 2009) e cedidas pelo Laboratório de Gerenciamento Costeiro Integrado (LABGERCO), da Universidade Federal do Rio Grande (FURG).

A legislação vigente para Áreas de Preservação Permanente (APP) definiu as faixas de distância aplicadas para o Mapa de Base Legal Ambiental (MBLA): (1) $300 \mathrm{~m}$ da linha de costa marinha em direção ao continente considerados como APP com função de proteger a restinga (CONAMA, 2002); (2) $30 \mathrm{~m}$ das margens de rios com a função de proteger a mata ciliar (Brasil, 2012); (3) $50 \mathrm{~m}$ da linha de costa da lagoa em direção ao continente (Brasil, 2012); e (4) $50 \mathrm{~m}$ do canal adutor de água, de acordo com resolução do COMDEMA. Por ser uma região plana, não foi necessário definir APPs resultantes de declividade de encostas (Brasil, 2012).

\subsection{Conversão e reclassificação dos dados}

Nesta etapa, o mapa de cobertura do solo foi reclassificado em um mapa booleano ( 0 ou 1 ), identificando os ambientes que são considerados APP (matas nativas, dunas, banhados e marismas). Os dados vetoriais foram convertidos em dados ras- ter ${ }^{4}$, possibilitando o cruzamento e a sobreposição (overlay) deste mapa com as faixas de distância descritas no item anterior, o que gerou o MBLA.

\subsection{Obtenção de dados sobre políticas} públicas de ordenamento territorial no município e processamento

Foram levantados os dados geoespaciais das UPs e Zoneamento Ecológico-Econômico Municipal (ZEEM). Estes dados foram cedidos pelo Programa Geosaúde, do Curso de Geoprocessamento do Instituto Federal de Educação, Ciência e Tecnologia do Rio Grande do Sul - IFRS, e LABGERCO, do Instituto Oceanográfico da Universidade Federal do Rio Grande - FURG, respectivamente.

O ZEEM é classificado em quatro zonas: (1) Área de Preservação, (2) Área de Conservação, (3) Área de Desenvolvimento e (4) Área de Recuperação. Já o Plano Diretor é classificado em 10 tipos: (1) Área Central, (2) Área Funcional, (3) Corredor de Comércio e Serviços, (4) Polo de Comércio e Serviços, (5) Unidade Funcional, (6) Unidade Industrial, (7) Unidade Mista, (8) Unidade Residencial, (9) Área Urbana de Ocupação Rarefeita (AUOR) e (10) Área de Interesse Ambiental (AIA).

Como na Área de Estudo não há nenhuma área classificada como Área de Recuperação e como a área mapeada pelo Plano Diretor não cobre toda a extensão do presente estudo, convencionou-se usar as seguintes classificações para a análise: (1) Área de Preservação; (2) Área de Conservação, (3) Área de Desenvolvimento e (4) Áreas de Omissão. Foi

\footnotetext{
3 Shapefile é o formato mais comum de dados vetoriais, desenvolvido e regulamentado pelo grupo Esri para armazenar a posição, o formato e os atributos de feições geográficas.

4 Matriz de células, em que estão associados valores que permitem conhecer o objeto em forma de imagem digital. Cada célula denomina-se pixel e é endereçada por um par de coordenadas (linha, coluna).
} 
realizada então a reclassificação do mapa de UPs e do ZEEM, definindo as classes utilizadas para a comparação entre os instrumentos (Tabela 2). Por fim, os dados vetoriais foram convertidos para raster para os cálculos de sobreposição.

TABELA 2 - Atribuição de números digitais para cada classe definida pelo ZEEM e Plano Diretor Municipal.

\begin{tabular}{lll}
\hline & Classe & Valor \\
\hline \multirow{3}{*}{ ZEEM } & Preservação & 1 \\
& Conservação & 2 \\
& Desenvolvimento & 3 \\
\hline \multirow{4}{*}{ Unidades de } & Área Central & 3 \\
& Área Funcional & 3 \\
& Corredor de Comércio e Serviços & 3 \\
& Polo de Comércio e Serviços & 3 \\
& Unidade Funcional & 3 \\
& Unidade Industrial & 3 \\
& Unidade Mista & 3 \\
& Área Urbana de Ocupação Rarefeita & 2 \\
& Área de Interesse Ambiental. & 1 \\
\hline
\end{tabular}

\subsection{Sobreposição espacial dos instrumentos de ordenamento territorial}

Nesta etapa, foi realizada uma normalização nos dados para padronizar a área de abrangência de todos os mapas e uma reclassificação do mapa da base legal ambiental para que tivesse as mesmas classes dos outros instrumentos (ZEEM e UPs). Desta forma, as áreas de APP foram classificadas com o número digital 1 (preservação) e as áreas de não APP com o número Digital 3 (Desenvolvimento).

Os dados foram sobrepostos com o auxílio da metodologia de tabulação cruzada (crosstab), que cria uma classe para cada combinação diferente de números digitais das tabelas iniciais. Optou-se por analisar os dados em comparação por pares
(UPs x ZEEM; UPs x MBLA; ZEEM x MBLA) e foram estabelecidos padrões de conflito, realizando uma reclassificação atribuindo 4 graus de conflito, conforme a Tabela 3 .

TABELA 3 - Graus de conflito de acordo com as combinações de classes dos instrumentos.

\begin{tabular}{cclc}
\hline \multicolumn{2}{c}{ Classes } & \multicolumn{2}{l}{ Grau de Conflito } \\
\hline Preservação & Preservação & 1 & Sem Conflito \\
Preservação & Conservação & 2 & Moderado \\
Preservação & Desenvolvimento & 3 & Alto \\
Preservação & Omisso & 4 & Omisso \\
Conservação & Omisso & 4 & Omisso \\
Desenvolvimento & Conservação & 2 & Moderado \\
Desenvolvimento & Desenvolvimento & 1 & Sem conflito \\
Desenvolvimento & Omisso & 4 & Omisso \\
\hline
\end{tabular}

\subsection{Análise dos resultados}

Os dados foram analisados de forma quali-quantitativa, por meio de mapa de cobertura do solo, de APPs e de conflitos; cálculos das áreas de cobertura do solo, de APPs e de conflitos; referências bibliográficas e documentais e gráficos de coluna, representando a área para cada tipo de cobertura do solo e a porcentagem de área produzidos no software livre $R$-Statistics.

\section{Resultados e discussão}

\subsection{Mapa de cobertura do solo}

O método de classificação que apresentou maior acurácia foi o MaxLike $(\mathrm{k}=0,78)$, seguido por MinDist $(\mathrm{k}=0,70)$ e SAM $(\mathrm{k}=0,70)$. A acurácia por meio da análise visual também foi maior para o MaxLike, que é o método mais utilizado e bem descrito pela literatura para cenas naturais, sendo 
conhecido como classificador ótimo (Erbek et al., 2004). Quando a análise foi realizada por tipo de ambiente, a maior confusão nos três métodos testados ocorreu entre as classes de mata nativa e mata exótica, o que já era previsto, devido à semelhança espectral destes alvos.

Na Figura 3, é possível verificar o Mapa de Cobertura do Solo gerado para a área de estudo com o método MaxLike.

A maior parte da área de estudo está coberta por vegetação de campos (50,5\%), seguida por banhados e marismas $(25,2 \%)$, solo exposto $(12,6 \%)$, dunas $(5,3 \%)$, matas exóticas $(2,8)$, matas nativas
$(2,4 \%)$ e lagoas $(1,2 \%)$ (Figura 4). A predominância é de campos, que é uma das principais características do bioma pampa, e também as peculiaridades da vegetação costeira da metade sul do Rio Grande do Sul. Na região lagunar, há ecossistemas de áreas úmidas, como os banhados do Senandes, as marismas do Saco da Mangueira (presentes na área de estudo), como também os banhados da Reserva Ecológica do Maçarico e da Estação Ecológica do Taim, localizados mais ao sul da área de estudo. Estes ecossistemas abrigam diversas espécies ameaçadas ou vulneráveis.

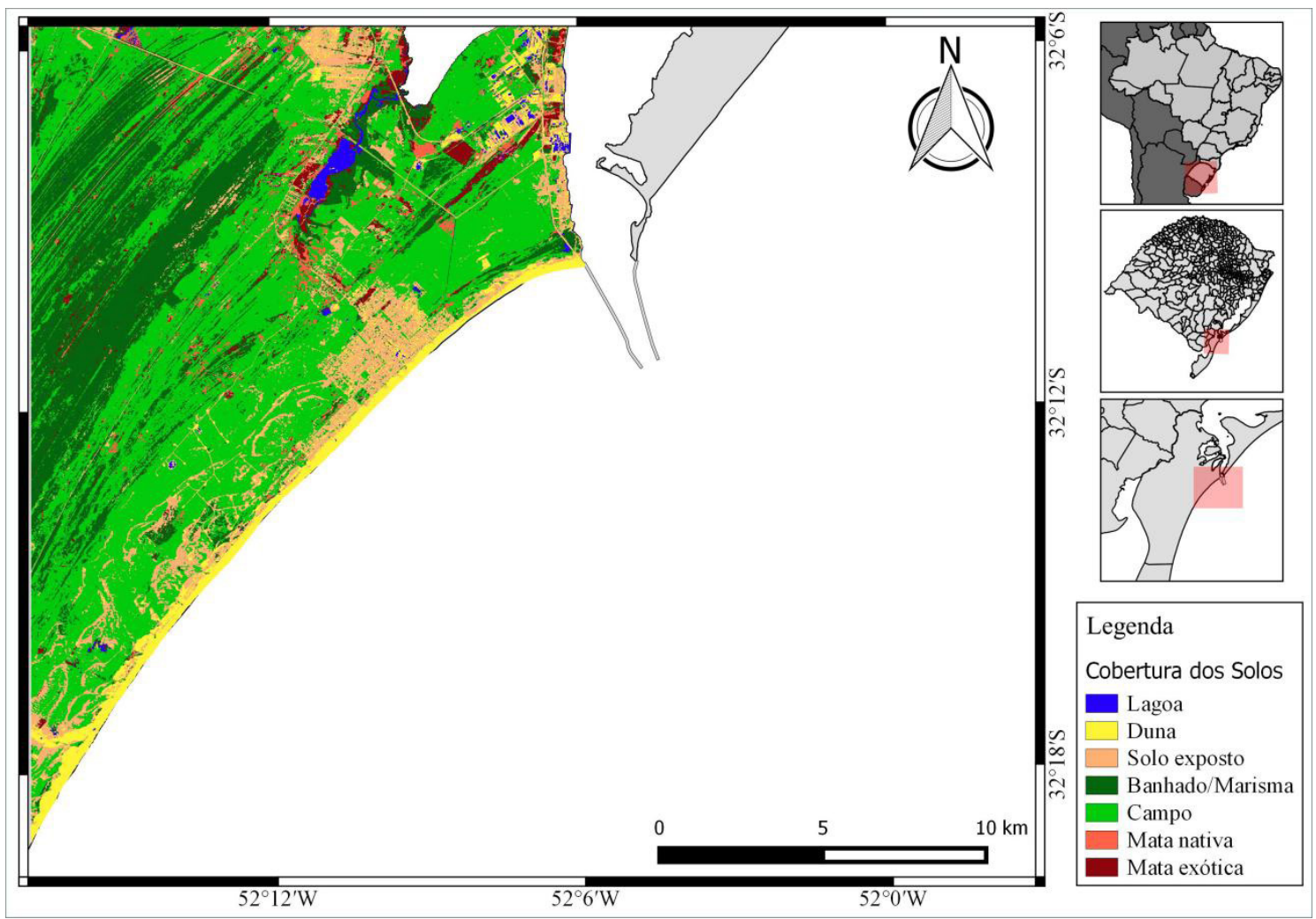

FIGURA 3 - Mapa de cobertura do solo. 


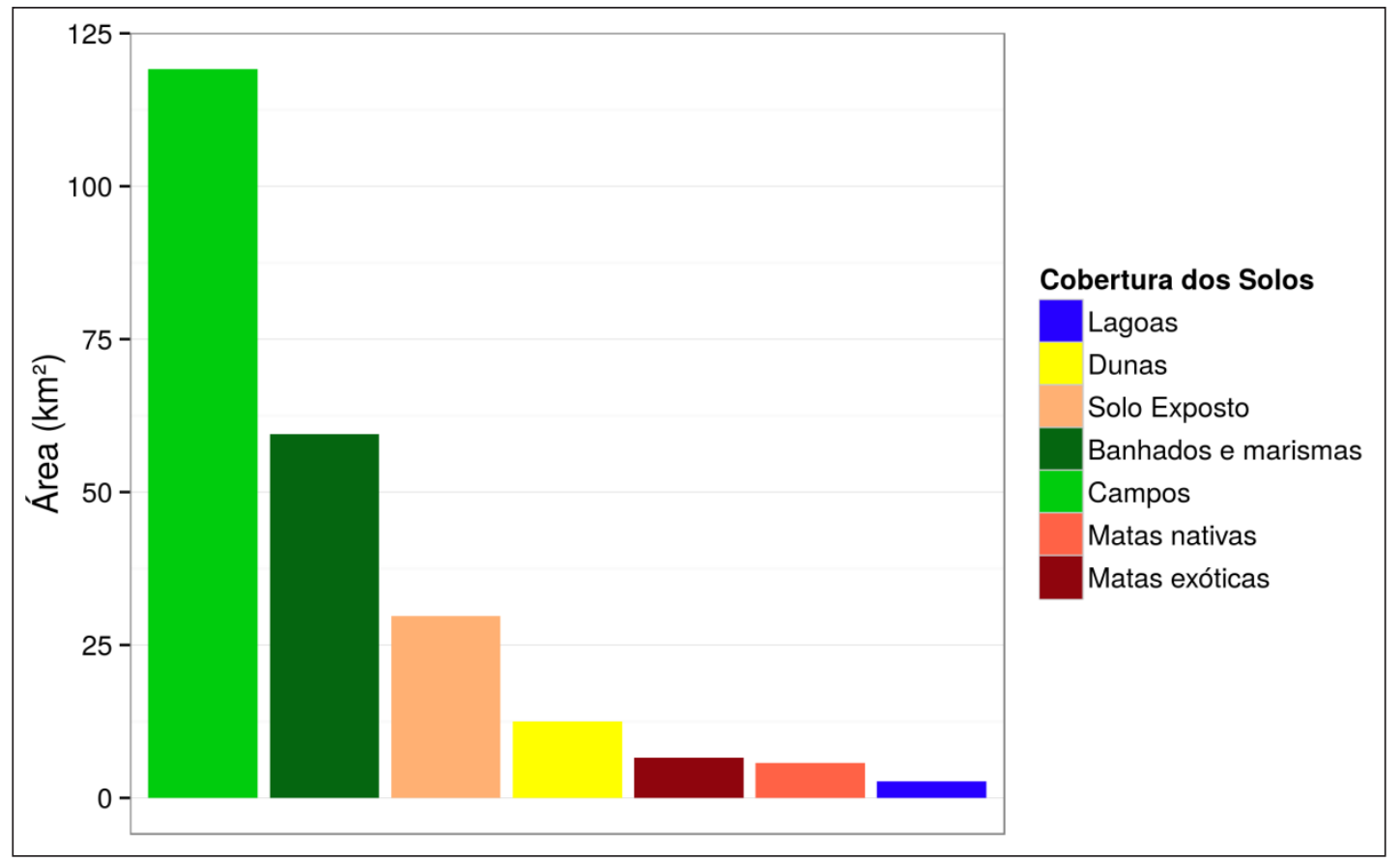

FIGURA 4 - Área calculada para cada tipo de cobertura dos solos.

\subsection{Mapa da base legal ambiental}

Aproximadamente $34 \%$ da área mapeada foi definida como APP, o que equivale a $81.5 \mathrm{~km}^{2}$. Muitas destas áreas estão distribuídas de forma fragmentada, como ocorre com a vegetação de banhado, que tem grande correlação com a formação geológica do município e das matas nativas. Desta forma, a aplicação do filtro serviu para a uniformização de áreas, embora possa mascarar algumas nuances importantes. Por tal razão, são importantes as escolhas do método e da área filtrada. Existem três tipos de banhado na região: (1) formados por acúmulo de água da chuva; (2) "afloramentos do lençol freático na base do sistema de dunas pleistocênicas e holocênicas, onde a pressão hidrostática exercida pelas dunas provoca um soerguimento temporário do lençol (durante os meses de verão tendem a secar)" (Costa \& Tagliani, 2011, p. 159); e (3) banhados formados nos terraços lagunares mais baixos nas margens da laguna (que podem ser temporários ou permanentes) (Costa \& Tagliani, 2011).

$\mathrm{Na}$ área de estudo, a maior parte dos banhados pertence aos dois primeiros tipos. Porém, vale ressaltar que a imagem utilizada foi capturada em janeiro, o que evidencia uma permanência de áreas de banhados mesmo em períodos de menor precipitação e que estes ambientes podem ser expandidos em períodos chuvosos.

As áreas de dunas aparecem como típicas de cordões de dunas, bastante degradadas pela ação do homem com a "retirada sistemática de areia, pastoreio, abertura de número excessivo de ruas 
para acesso à praia, depósito irregular de resíduos sólidos, ocupação humana irregular e desordenada, pisoteio e, recentemente, como pista para veículos off-road" (Carvalho et al., 2011, p. 172).

As áreas de mata nativa se resumem a dois pequenos aglomerados que ainda resistem: a mata ciliar nos entornos do Arroio Bolaxa e um maciço dentro do DIRG, próximo ao cruzamento entre o Corredor do Bolaxa e a BR-392. De acordo com o Inventário Florestal Contínuo do Rio Grande do Sul (2002), a região da Bacia Hidrográfica São Gonçalo-Mirim possui cobertura florestal que representa 1,396\% da cobertura do Estado, sendo $1,36 \%$ de florestas nativas em seus estágios iniciais, médios e avançados de sucessão. O MBLA pode ser visualizado na Figura 5.

\subsection{Mapa de conflitos entre instrumentos legais de ordenamento territorial}

Previamente ao resultado da sobreposição dos instrumentos e dos conflitos decorrentes do mesmo, é importante apresentar os mapas brutos, apenas classificados de acordo com a metodologia, para que se possa entender o cruzamento dos dados. Portanto, apresentam-se na Figura 6 o ZEEM e as UPs, classificados em preservação, conservação e desenvolvimento.

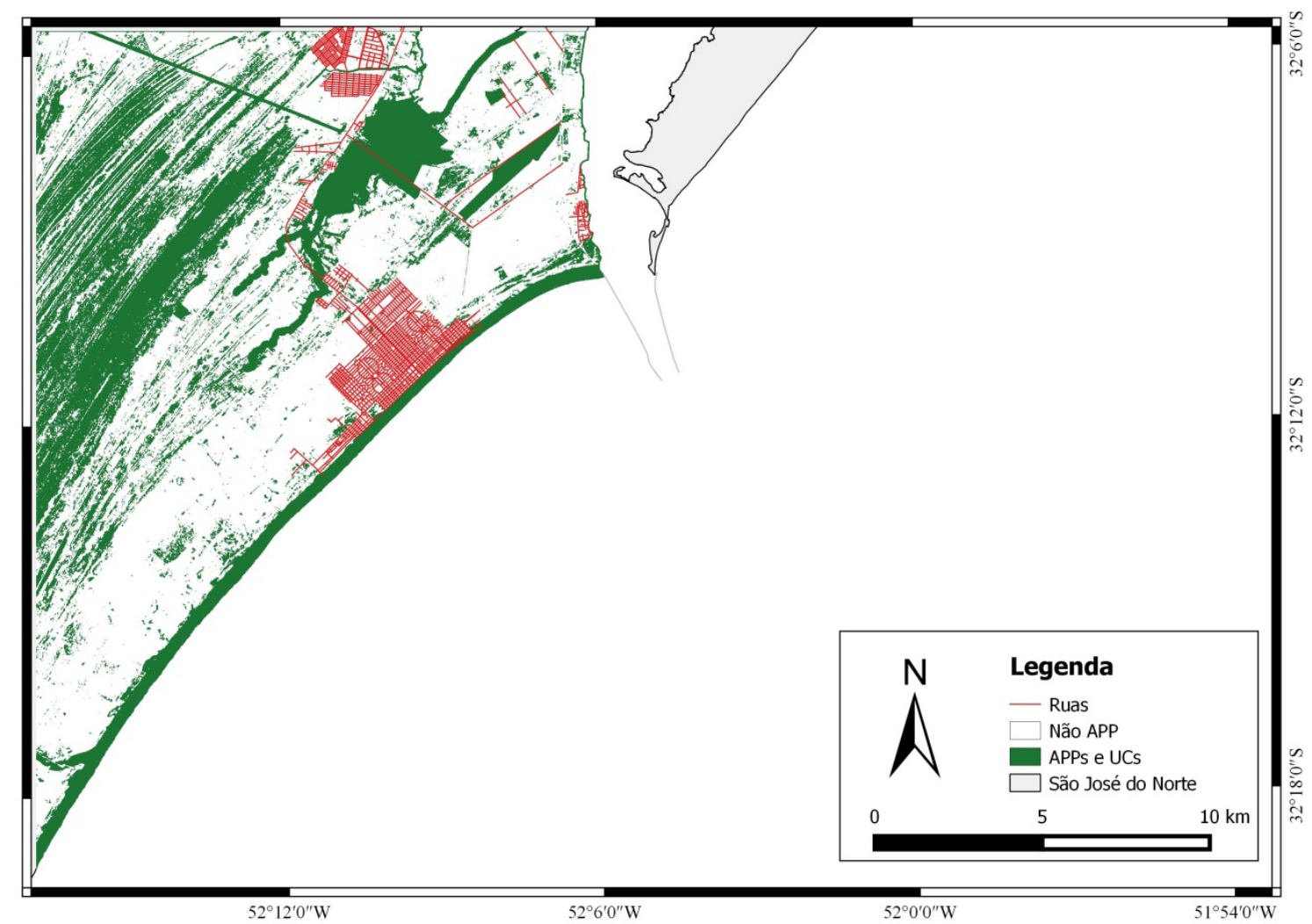

FIGURA 5 - Áreas protegidas por legislação ambiental (Áreas de Preservação Permanente e Unidades de Conservação). 
É possível verificar que as UPs do Plano Diretor são muito mais detalhadas do que o ZEEM, porém, não cobrem grande parte da área de estudo (Figura 6).

Quanto aos mapas de conflitos, obteve-se como produto da sobreposição dos instrumentos três mapas (com quatro categorias: Sem Conflito, Moderado, Alto e Omisso) que podem ser visualizados na Figura 7.

Em verde é possível verificar as áreas em que não há divergência entre os instrumentos para o planejamento de uso da área, em amarelo as áreas que divergem, mas de forma não tão grave (conflito entre área de conservação e preservação ou desen- volvimento e conservação), em vermelho as áreas com alto conflito (preservação e desenvolvimento) e, em cinza, as áreas em que um dos instrumentos não regulou.

Alguns conflitos detectados se devem a problemas de escala ou de divergência de bases cartográficas. As UPs foram elaboradas em escala 1:10.000, o ZEEM em escala 1:100.000 e o MBLA em escala 1:25.000. Isto fez com que ocorressem alguns erros de borda, como é possível verificar na área costeira e nas margens da Lagoa dos Patos e do Saco da Mangueira.

Outra debilidade encontrada foi que o Plano Diretor é omisso em grande parte da área de estu-
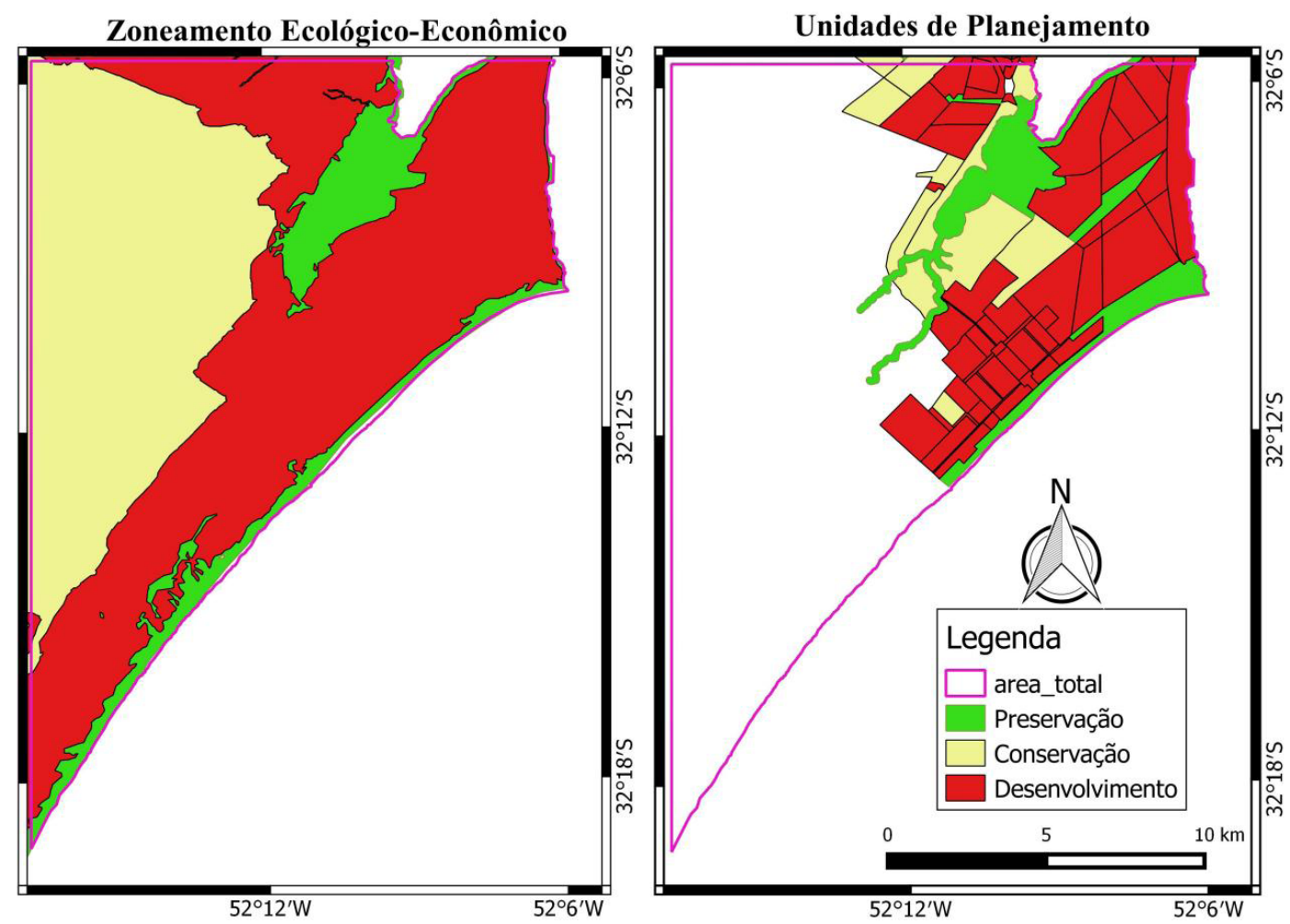

FIGURA 6 - Mapa do Zoneamento Ecológico-Econômico e Unidades de Planejamento classificadas em Preservação, Conservação e Desenvolvimento. 


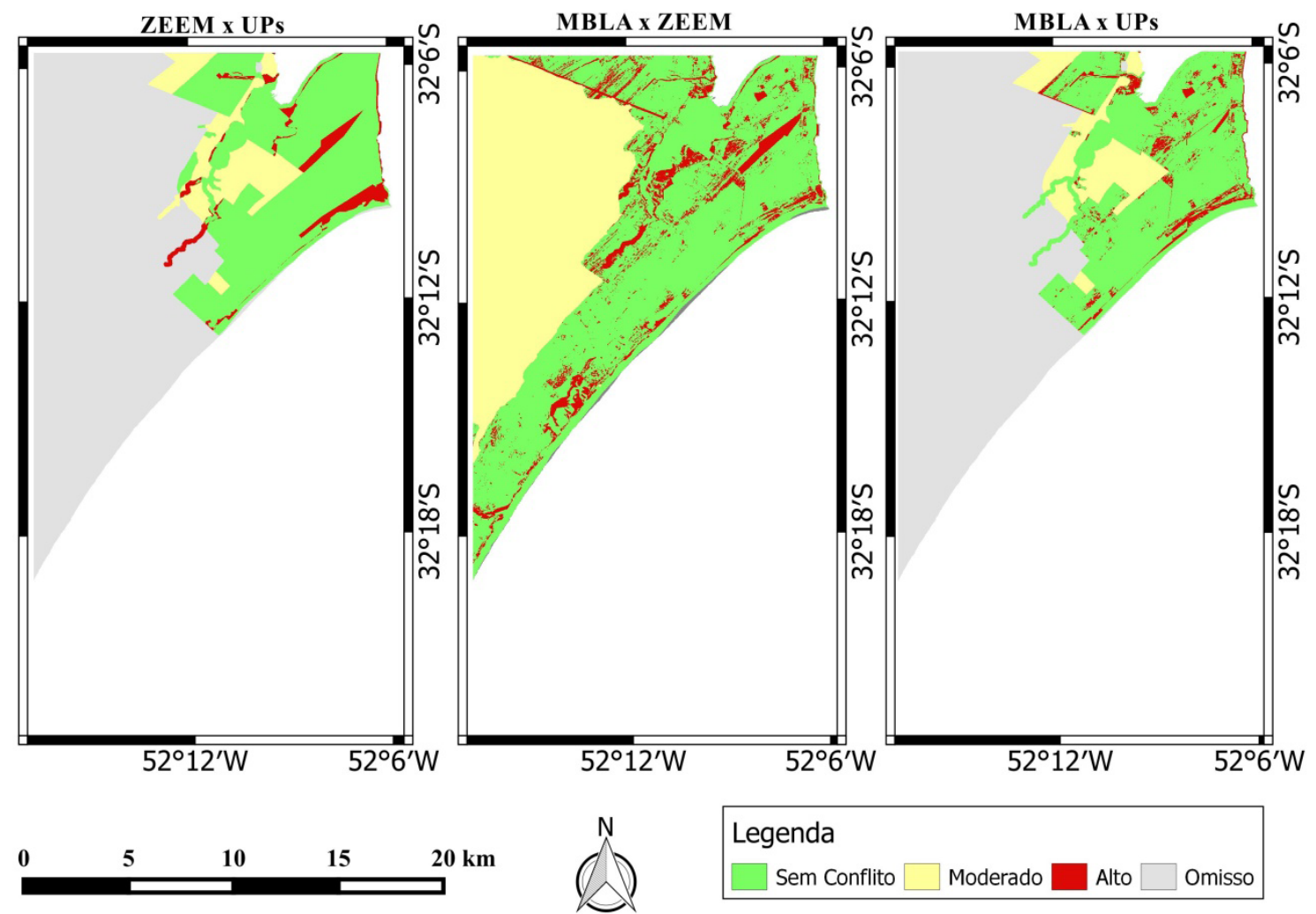

FIGURA 7 - Mapa de conflitos entre os instrumentos de ordenamento territorial.

do. Este instrumento foi elaborado apenas para as áreas urbanas, diverso do que estabelece o Estatuto das Cidades. O fato de não ser uma área urbana consolidada contribui para o estado de conservação destes ecossistemas. Porém, essas lacunas no planejamento são muito perigosas do ponto de vista ambiental, uma vez que estas áreas estão sujeitas a expansão urbana.

O Plano Diretor Participativo: Guia para a elaboração pelos municípios e cidadãos (Ministério das Cidades, 2005) apresenta de forma sintetizada a proposta da política urbana construída pelo Ministério das Cidades e dispõe que
O Plano Diretor deve abranger a totalidade do território do município - áreas urbanas e rurais [...] a leitura socioterritorial da zona rural deve analisar as tendências de desenvolvimento das atividades agrícolas e não agrícolas. A disponibilidade de um Zoneamento Ecológico Econômico pode fornecer informações valiosas para as análises. (Ministério das Cidades, 2005, p. 61).

\section{Ainda diz que}

A sistematização da leitura socioterritorial das zonas rurais condiciona-se pelos objetivos do Plano Diretor expressos no macrozoneamento urbano e rural [...] no macrozoneamento rural é importante iden- 
tificar áreas com solos, topografia, acessibilidades e infraestruturas adequadas para as diversas formas de produção agropecuária, extração vegetal, exploração mineral, usos não agrícolas, como o turismo, chácaras de veraneio, moradias permanentes, dentre outras. $\mathrm{O}$ princípio da democratização do acesso à terra rural deve orientar a demarcação destas macrozonas. Assim como o princípio da sustentabilidade ambiental deve orientar a classificação das áreas de preservação permanente e de reserva legal, segundo o estado de conservação dos recursos naturais e sua capacidade de regeneração nos casos de degradação. Tal princípio deve nortear também a identificação dos locais com maciços vegetais compostos de diversas espécies em distintos estágios de preservação (Ministério das Cidades, 2005, p. 61-62, grifos nossos).

Desta forma, podemos concluir que, 14 anos após a instituição do Estatuto das Cidades, o município do Rio Grande segue em desacordo por não apresentar um macrozoneamento das zonas urbanas e rurais. Possui apenas as UPs para a área urbana que abrange o centro da cidade. Há planejamento em elaboração na área urbana da Vila da Quinta e nenhum planejamento para as áreas urbanas do Povo Novo e Taim, também delimitadas nos anexos do Plano Diretor.

Como as UPs têm uma escala mais detalhada (1:10.000), elas acabam levando em conta nuances que não foram consideradas no ZEEM (1:100.000), como as APs do DIRG, a área de banhado em frente ao terminal de containers (TECON), o Arroio Vieira e parte do banhado abrigado pela APA da Lagoa Verde (Figura 6).

Existe uma maior área de conflitos entre o MBLA e o ZEEM do que na sobreposição entre o ZEEM e UPs. Apenas os $300 \mathrm{~m}$ da linha de costa marítima, os 50m da linha de costa lagunar e parte da APA da Lagoa Verde são considerados como de preservação no ZEEM. Toda a parte em amarelo no mapa da Figura 7 é classificada como conservação e, pela metodologia adotada neste trabalho, os conflitos de áreas de conservação com APP ou não APP são moderados, não sendo possível separar onde o Mapa Legal é mais permissivo ou mais restritivo que o ZEEM.

Com relação aos conflitos entre as UPs e o MBLA (Figura 6), houve conflitos tanto negativos do ponto de vista preservacionista como positivos. Em alguns locais, o Mapa das UPs é mais restritivo que o MBLA, como ocorre na região do Arroio Vieira. Ou seja, o Plano Diretor acaba por proteger uma área que, segundo o Mapa Ambiental de Base Legal, não seria classificado como APP. Ocorreram também conflitos com áreas de banhado, áreas de dunas (principalmente decorrentes de erro na classificação) e a presença de algumas áreas de desenvolvimento em parte da APP de restinga (300 $\mathrm{m}$ da preamar).

Aqui se destaca a importância da delimitação das APPs, já que a sua sobreposição aos instrumentos poderia minimizar os conflitos entre eles. Segundo Gandra (2008), houve a realização de dois mapas de Zoneamento Ecológico Econômico Municipal: um mais detalhado, com a delimitação das APPs, e outro simplificado, para facilitar a tomada de decisões, porém,

\begin{abstract}
[...] deve ficar claro que o mapa simplificado deverá ser utilizado apenas para versões impressas, enquanto que para a análise de alternativas de localização de empreendimentos, a versão digital do ZEEM bruto deverá ser utilizada nas escalas adequadas. Isso evitaria que se desconsiderem importantes unidades naturais, como as matas nativas, e as descontinuidades espaciais dos banhados e outras unidades da região (Gandra, 2008, p. 52).
\end{abstract}

No entanto, o que se verifica na prática é o uso do instrumento simplificado (o analisado neste trabalho) como meio de consulta para a viabilidade 
de empreendimentos. Vale ainda ressaltar que o Plano Municipal de Meio Ambiente se encontra em forma digital, está disponível no site da Prefeitura Municipal e cita seus instrumentos como constantes em anexo. No entanto, tais anexos não estão disponíveis.

Gandra (2008) ainda constatou que, na simplificação do instrumento, houve diminuição das áreas de preservação (13.400 hectares) e conservação (7.234 hectares) do município e um aumento proporcional das áreas de desenvolvimento, o que se torna perigoso para a conservação das APPs, principalmente as pequenas manchas.

Não se pode deixar de salientar a importância destes ambientes na manutenção da biodiversidade e da saúde e bem-estar da população, uma vez que os banhados destacam-se pela

[...] diversidade biológica, produtividade, armazenamento de água, controle de inundações, recarga de aquíferos subterrâneos, purificação da água e estabilidade climática; além de proporcionarem condições favoráveis à produção de peixes e à agricultura (Maltchik, 2003, apud Carvalho \& Ozório, 2007, p. 87).

O aterro e a ocupação destes ambientes, além de trazer consequências ambientais irreversíveis, causam inundações e muitos transtornos para seus ocupantes.

Junk et al. (2014) explicitam que, apesar da extensão geográfica, da diversidade e da importância econômica dos ambientes úmidos brasileiros, eles raramente são mencionados nas legislações federal, estaduais ou ambientais e não existe uma política nacional para regular a proteção destas áreas, o que as deixa mais vulneráveis e suscetíveis a alterações antrópicas.

Da mesma forma, a área de restinga é de relevante importância, pois abriga diversas espécies e serve de fixadora dos cordões de dunas, evitando que as ressacas atinjam as áreas urbanas. As matas ciliares servem como fixadoras do solo nas margens de rios, evitando erosões e filtrando a água, além de servirem de abrigo e criadouro de diversas espécies, assim como as marismas.

Foi maior a área de conflitos entre o ZEEM e Mapa da Base Legal (Figura 8), o que pode ser explicado pela diferença de escala (1:100.000 e 1:25.000, respectivamente) destes instrumentos e a simplificação para as tomadas de decisão. Porém, deve-se destacar que o Plano Ambiental Municipal, ao dispor da metodologia de classificação do ZEEM, estabelece que (a classe) zonas de preservação ambiental

São constituídas pelas áreas de marismas, banhados de água doce permanentes, as ilhas estuarinas da Pólvora, Ilha do Mosquito, dunas vivas e matas nativas, que por sua importância e sensibilidade ecológica requerem medidas de preservação das condições naturais. Correspondem às Áreas de Preservação Ambiental definidas pela Resolução 303/2002 do CONAMA e, portanto, regradas de acordo com essa normativa (Rio Grande, 2008).

Portanto, tais áreas deveriam, obrigatoriamente, constar no instrumento. Deve-se ainda considerar que as APPs são definidas em lei, mas não delimitadas espacialmente, gerando uma certa subjetividade. Torna-se, portanto, imprescindível que os municípios façam o mapeamento destas áreas para salvaguardar estes ecossistemas. Por outro lado, os outros dois instrumentos são reconhecidos pelo município como instrumentos de gestão, utilizados no cotidiano das decisões administrativas e políticas. A sobreposição de forma harmônica e integrada destes instrumentos poderia, dessa forma, ser um orientador para a distribuição espacial de atividades e parcelamento do solo no município. 


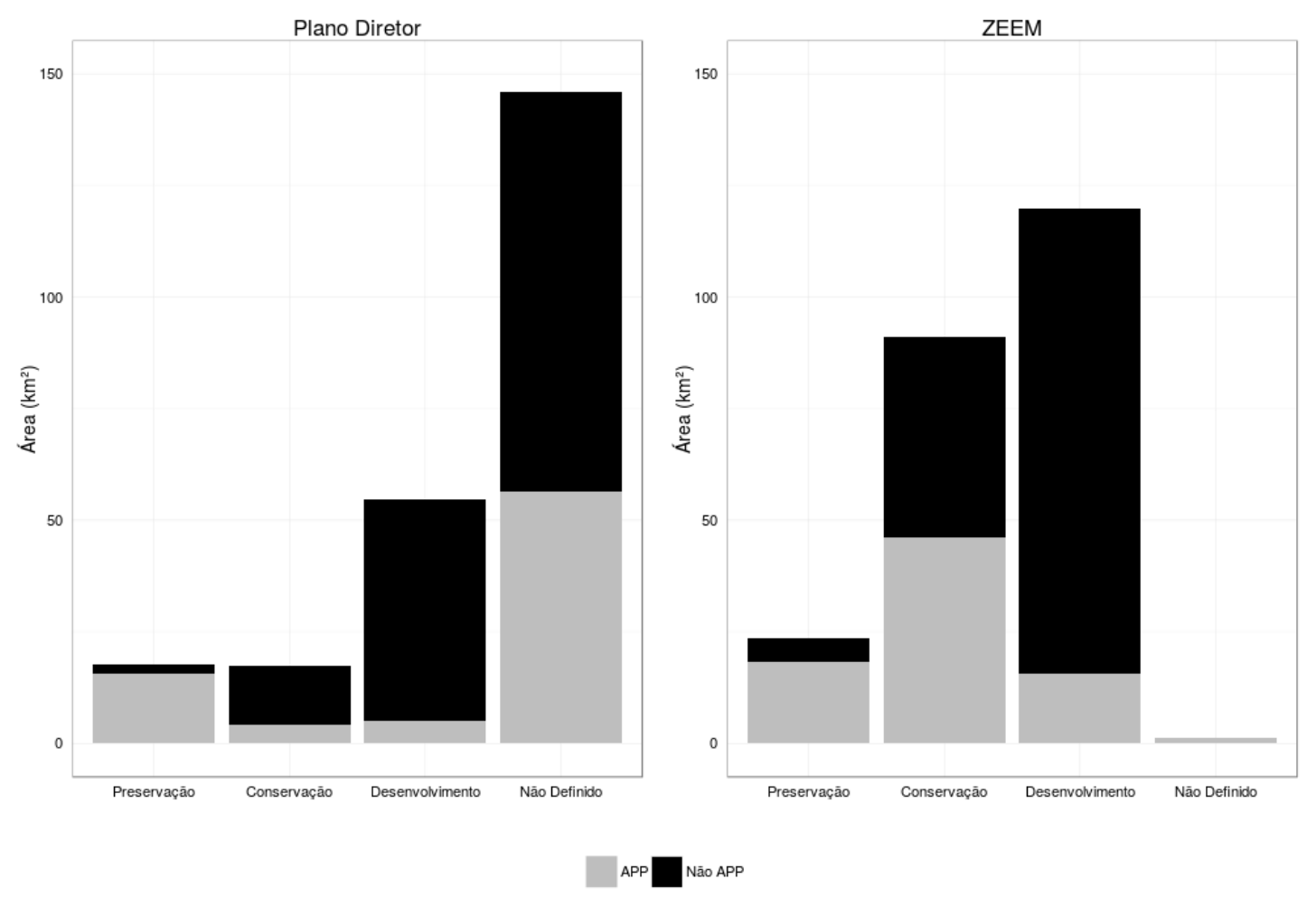

FIGURA 8 - Área de APP para cada tipo de uso definido pelos instrumentos analisados.

Para Moraes (1999), o ideal é não dicotomizar o "urbano" e o "ambiental" na formulação de políticas públicas. Entretanto, a estrutura institucional brasileira, consolidada de forma separada e não comunicante por meio das figuras do Ministério das Cidades (urbano) e do Ministério do Meio Ambiente (ambiental) (se reproduzindo nas secretarias e agências estaduais e municipais), se materializa como um empecilho na integração das temáticas e, consequentemente, das políticas públicas. Vale ainda salientar que o ministério responsável pela política de ordenamento territorial é um terceiro componente - o Ministério de Integração Nacional.

A implementação de muitas políticas públicas que se sobrepõem e, em alguns momentos, se con- tradizem, gera insegurança jurídica na população. Tal condição poderia ser resolvida com vontade política e investimento em um sistema integrado e interinstitucional de informações, com políticas públicas claras, bem definidas e espacializadas em uma mesma base cartográfica.

O ZEEM é, de fato, um instrumento relevante, mas, no caso de Rio Grande, não possui força de lei, uma vez que não foi sancionado pelo município e apenas aprovado pelo COMDEMA. Políticas hierárquicas que não se comunicam e se contradizem possuem sua efetividade diminuída. Por ser o único instrumento com força de lei (e respaldado por uma importante lei federal), o Plano Diretor tem maior influência na tomada de decisões. Mas 
o que fazer em áreas em que o Plano Diretor não dispõe sobre seu uso e qual a real efetividade do ZEEM? Enfim, são muitas discussões possíveis que demandam a necessária problematização para que possamos progredir e evoluir para políticas públicas mais claras, concisas, eficazes e efetivas, capazes de acabar com a dicotomia nos campos político, teórico e prático. Enfim, políticas públicas integradoras que considerem os elementos urbanos e rurais no âmbito do contexto ambiental.

Os autores do ZEEM o consideram um instrumento balizador do processo de ordenamento territorial necessário para a obtenção das condições de sustentabilidade ambiental do desenvolvimento do município do Rio Grande. Este deve estar em consonância com as diretrizes do Zoneamento Ecológico Econômico Costeiro (ZEEC) do Programa Estadual de Gerenciamento Costeiro do Rio Grande do Sul, com o ZEE do território nacional e ainda com o Plano Diretor municipal (Rio Grande, 2008). No entanto, o que se verificou é que este instrumento não está em consonância com o Plano Diretor. Idealmente, deve haver uma atualização dos dados para instrumentos de gestão que se comuniquem e se complementem, reduzindo a insegurança jurídica da população, bem como da própria administração municipal frente a instrumentos contraditórios.

Vale salientar que o Estatuto das Cidades define que as leis municipais que instituem os planos diretores municipais devem ser revistas pelo menos de 10 em 10 anos; considerando que a lei municipal é de 2008 e que deve ocorrer essa revisão em no máximo dois anos, é importante que se forme uma base robusta de dados e discussões "de forma integrada com os demais fóruns de discussão atuantes no município" (Ministério das Cidades, 2005, p. 32) acerca do futuro da cidade e da proteção destes ecossistemas.

\section{Considerações finais}

A metodologia desenvolvida e aplicada neste trabalho mostrou-se eficaz, gerando um mapa de Cobertura do Solo a partir de uma imagem RapidEye ${ }^{\circledR}$, um MBLA a partir das restrições legais impostas ao uso do solo (Áreas de Preservação Permanente, Unidades de Conservação, resoluções municipais, entre outros) e a análise de conflitos espaciais entre dois instrumentos de ordenamento territorial adotados pelo município e o MBLA gerado.

Adicionalmente, a metodologia utilizada é replicável para outros municípios, uma vez que usa softwares livres e imagens orbitais obtidas de forma gratuita.

Os mapas de cobertura dos solos e de Áreas de Preservação Permanente evidenciaram a importância de se ter esta informação georreferenciada como instrumento de gestão nas decisões sobre a viabilidade de empreendimentos e expansão urbana, devido a sua grande complexidade e fragmentação. Da mesma maneira, fica clara a insuficiência dos macrozoneamentos (como o ZEEM atualmente utilizado) para as tomadas de decisão no cotidiano das prefeituras municipais.

Os mapas de conflitos evidenciaram a existência de conflitos entre os três mapeamentos de diversas naturezas, como conflitos de escala e de bases cartográficas, mas também decorrentes da decisão de suavização dos dados. A situação mais crítica refere-se ao ZEEM, ao não considerar diversas peculiaridades locais. O retorno do uso do ZEEM não simplificado, ou a sua atualização em maior escala cartográfica, poderia minimizar estes conflitos e salvaguardar com mais ímpeto os ecossistemas em discussão.

Evidenciou-se também uma desconformidade com a Lei Federal do Estatuto da Cidade, pelo 
fato de o município não possuir, dentro do plano diretor, um zoneamento para a totalidade de sua área, apresentando apenas as UPs para a principal área urbana (que envolve o centro do município), sem um planejamento para as demais áreas urbanas (Quinta, Povo Novo e Taim) e, muito menos, para as áreas rurais. Tal fato coloca em risco a conservação destes ecossistemas.

Deve-se ressaltar ainda que, ao agrupar diferentes zoneamentos em quatro categorias, se perde a riqueza dos dados, como as comparações entre conservação e preservação e conservação e desenvolvimento, que foram todas consideradas como grau moderado de conflito. Da mesma forma, as Unidades "Área de Interesse Ambiental" do Plano Diretor não são necessariamente Áreas de Preservação Permanente.

Por fim, é importante ressaltar que o cruzamento espacial dos instrumentos mostrou que o ZE-

\section{Referências}

Andrade, A. C.; Francisco, C. N.; Almeida, C. M. Desempenho de classificadores paramétrico e não paramétrico na classificação da fisionomia vegetal. Revista Brasileira de Cartografia, 66, 349-363, 2014. Disponível em: <http:// www.lsie.unb.br/rbc/index.php/rbc/article/view/546/682>.

Brasil. Lei $n^{\circ}$ 4.771, de 15 de setembro de 1965. Institui o novo Código Florestal (revogada). Brasília: DOU de 16/09/1965.

Brasil. Lei n ${ }^{\circ}$ 6.938, de 31 de agosto de 1981. Dispõe sobre a Política Nacional do Meio Ambiente, seus fins e mecanismos de formulação e aplicação, e dá outras providências. Brasília: DOU de 02/02/1981.

Brasil. Constituição da República Federativa do Brasil, 5 de outubro de 1988. Brasília, Centro Gráfico, 1988.

Brasil. Lei $n^{\circ}$ 10.257, de 10 de julho de 2001. Regulamenta os arts. 182 e 183 da Constituição Federal, estabelece di-
EM não está em consonância com as UPs do Plano diretor e nem com a legislação ambiental vigente e necessita de reavaliação, revisão e implementação na forma de lei, de maneira que estes instrumentos se complementem rumo a um objetivo comum, que é a utilização racional e sustentável do espaço.

Ademais, a geração do mapa da base legal ambiental em escala compatível à gestão urbana permitirá um refinamento dos dados que poderá embasar novas pesquisas e até mesmo o governo local na geração de políticas públicas que sejam claras, precisas, acuradas e integradas.

\section{Agradecimentos}

Ao IFRS pela bolsa BICET do Edital 04/2014 vinculado ao Edital PROPPI No 008/2014 - FOMENTO INTERNO 2015/2016.

retrizes gerais da política urbana e dá outras providências. Brasília: DOU de 11/07/2001.

Brasil. Decreto $n^{\circ} 4.297$, de 10 de julho de 2002. Regulamenta o art. $9^{\circ}$, inciso II, da lei ${ }^{\circ} 6.938$, de 31 de agosto de 1981, estabelecendo critérios para o Zoneamento Ecológico Econômico do Brasil - ZEE, e dá outras providências. Brasília: DOU de 11/07/2002.

Brasil. Lei $n^{\circ} 12.651$, de 25 de maio de 2012. Dispõe sobre a proteção da vegetação nativa e dá outras providências. Brasília: DOU de 28/05/2012.

Carvalho, A. B. P.; Ozorio, C. P. Avaliação sobre os banhados do Rio Grande do Sul, Brasil. Revista de Ciências Ambientais, 1, 83 -95. 2007.

Carvalho, R. V.; Silva, K. G. Pomar, F. S.; Crivellaro, C. V. L.; Gianuca, K. Manejo Ambiental da Dunas Costeiras do Município de Rio Grande. In: Tagliani, P. R. A.; Asmus, 
M. L. (Orgs.). Manejo costeiro integrado do estuário da Lagoa dos Patos: uma experiência de Gerenciamento Costeiro no Sul do Brasil. Rio Grande: Editora da FURG, 2011. p. 171-177.

Cicin-Sain, B.; Knecht, R. W. Integrated Coastal and Ocean Management: Concepts and Practices. Washington: Island Press, 1998.

CONAMA - Conselho Nacional do Meio Ambiente. Resolução $n^{\circ}$ 237, de 19 de dezembro de 1997. Brasília, 1997. Dispõe sobre a revisão e complementação dos procedimentos e critérios utilizados para o licenciamento ambiental. DOU de 22/12/1997.

CONAMA - Conselho Nacional do Meio Ambiente. Resolução $n^{\circ}$ 303, de 20 de março de 2002. Brasília, 2002. Dispõe sobre parâmetros, definições e limites de Áreas de Preservação Permanente. Brasília: DOU de 13/05/2002.

CONSEMA - Conselho Estadual do Meio Ambiente. Resolução $n^{\circ}$ 004, 28de abril de 2000. Porto Alegre, 2000. Dispõe sobre os critérios para o exercício da competência do Licenciamento Ambiental Municipal e dá outras providências. DOE de 02/05/2000.

Costa, C. S.; Tagliani, P. R. Cobertura vegetal e uso preponderante do espaço. In: Tagliani, P. R. (Org.). Ecologia da paisagem da restinga da lagoa dos Patos: uma contribuição para o manejo e conservação da reserva da biosfera. Rio Grande: Editora da FURG, 2011. p.109-160.

Erbek, F. S.; Özkan, C.; Taberner, M. Comparison of maximum likelihood classification method with supervised artificial neural network algorithms for land use activities. International Journal of Remote Sensing, 25, 1733-1748, 2004.

Gandra, T. B. R. Aspectos geomorfológicos e socioambientais como subsidios para o Zoneamento Ecológico-Econômico Costeiro - ZEEC. Rio Grande, Dissertação (Mestrado do Programa de Pós-Graduação em Oceanografia Física, Química e Geológica) - FURG, 2008.

Gonzalez, R. C.; Woods, R. E. Processamento de imagens digitais. 3. ed. São Paulo: Edgard Blucher, 2009. 780 p.

Jensen, J. R. Introductory Digital Image Processsing: A remote sensing perspective. 3 ed. Upper Saddle River: Pearson Prentice Hall, 2005.

Junk, W. J.; Piedade, M. T. F.; Lourival, R.; Wittmann, F.; Kandus, P.; Lacerda, L. D.; Bozelli, R. L.; Esteves,
F. A.; Nunes da Cunha, C.; Maltchik, L.; Schöngart, J.; Schaeffer-Novelli, Y.; Agostinho, A. A. Brazilian wetlands: their definition, delineation, and classification for research, sustainable management, and protection. Aquatic Conservation: Marine and Freshwater Ecosystems, 24, 5-22, 2014.

Maltchik, L. Áreas úmidas: importância, inventários e classificação. São Leopoldo: Unisinos, 2003. 79 p.

Mascarello, M. de A.; Santos, C. F. Rio Grande (RS): entre a expansão portuária e a invisibilidade social programada. In: Machado, C. R. S.; Santos, C. F.; Mascarello, M. A. (Orgs.). Conflitos ambientais e urbanos: casos do extremo sul do Brasil. 1. ed. Porto Alegre: Evangraf, 2015. p. 41-54.

Meneses, P. R.; Sano, E. E. Classificação pixel a pixel de imagens. In: Meneses, P. R.; de Almeida, T. (Orgs.). Introdução ao processamento de imagens de sensoriamento remoto. Brasília: UnB; CNPq, 2012. Disponível em: $<$ http:// www.cnpq.br/documents/10157/56b578c4-0fd5-4b9f-b82a-e9693e4f69d8>. Acesso em: 07 ago. 2015.

Mengatto Junior, E. A.; Silva, J. S. dos V. Imagens de alta resolução (RapidEye) para elaboração de mapas para planejamento e gerenciamento: estrada parque do Pantanal, MS. In: Anais do $5^{\circ}$ Simpósio de Geotecnologias no Pantanal. Campo Grande, 2014. p. 513-522.

Ministério da Integração Nacional. Documento base para a definição da Política Nacional de Ordenamento Territorial - PNOT (Versão preliminar). Brasília: Ministério da Integração Nacional, 2006. Disponível em: <http://www.fau.usp.br/ docentes/depprojeto/c_deak/CD/5bd/2br/3plans/2006pnot/ PNOT-v-preliminar.pdf $>$. Acesso em: jul. 2015.

Ministério das Cidades. Plano Diretor Participativo: guia para elaboração pelos municípios e cidadãos. Brasília: CONFEA, 2005. Disponível em: <http://polis.org.br/ wp-content/uploads/Plano-Diretor-Participativo-1.pdf>. Acesso em: ago. 2015.

Moraes, A. C. R. Contribuições para a gestão da Zona Costeira do Brasil: elementos para uma Geografia do litoral brasileiro. São Paulo: Hucitec; Edusp, 1999.

Nascimento, M. C.; Soares, V. P.; Ribeiro, C. A. A. S.; Silva, E. Delimitação automática de áreas de preservação permanente (APP) e identificação de conflito de uso da terra na bacia hidrográfica do rio Alegre. In: Anais do XII Simpósio Brasileiro de Sensoriamento Remoto, Goiânia, 2005. p. 2289-2296. Disponível em: <http://marte.sid.inpe. 
br/col/ltid.inpe.br/sbsr/2004/10.18.18.26/doc/2289.pdf>. Acesso em: 07 ago. 2015.

Polette, M.; Asmus, M. L. Meio ambiente marinho e impactos antrópicos. In: Castello, J. P.; Krug, L. C. (Org.). Introdução às Ciências do Mar. 1. ed. Pelotas: Textos, 2015. v. 1, p. 500-521.

Ribeiro, C. A. A. S.; Soares, V. P.; Oliveira, A. M. S.; Gleriani, J. M. O desafio da delimitação de áreas de preservação permanente. Sociedade de Investigações Florestais, 29(2), 203-212. 2005. Disponível em: <http://www.scielo.br/pdf/ rarv/v29n2/a04v29n2.pdf>. Acesso em: 07 ago. 2015.

Rio Grande Do Sul. Lei n. 11.520, de 03 de agosto de 2000. Institui o Código Estadual do Meio Ambiente do Estado do Rio Grande do Sul e dá outras providências, 2000. Disponível em: <http://www.al.rs.gov.br/legiscomp/arquivo. asp?idNorma=11\&tipo=pdf $>$. Acesso em: 07 ago. 2015.

Rio Grande. Lei $n^{\circ} 6.585$, de 20 de agosto de 2008. Dispõe sobre o Plano Diretor Participativo do Município do Rio
Grande e estabelece as diretrizes e proposições de desenvolvimento urbano municipal. Rio Grande, 2008.

Rio Grande. Plano Ambiental Municipal de Rio Grande. Prefeitura Municipal do Rio Grande e Fundação Universidade Federal do Rio Grande: Programa Costa Sul. 2011. Disponível em: <http://www.riogrande.rs.gov.br/pagina/ arquivos/arquivo/pmrg_4b6ab0baae70b-plano_ambiental. pdf>. Acesso em: 07 ago. 2015.

Santos, C. F.; Mascarello, M. de A. Meio Ambiente: uma análise sobre as posturas e políticas externa e interna do governo brasileiro. In: Anais do III Encontro Internacional de Ciências Sociais: crise e emergência de dinâmicas sociais. Pelotas: Editora Universitária UFPel, 2012. p. 1-17.

Silva, T. S.; Asmus, M. L. O uso dos sistemas de informação geográfica no manejo das Áreas de Preservação Ambiental do Distrito Industrial de Rio Grande, RS, Brasil. Competência, 2, 159-170, 2009. 